\title{
Preoperative function evaluation of the major lung resection: muscle-sparing axillary mini-thoracotomy versus video-assisted thoracoscopic surgery
}

\author{
Duilio Divisi, Gino Zaccagna, Mirko Barone, Roberto Crisci \\ Thoracic Surgery Unit, University of L'Aquila, “G. Mazzini” Hospital, Teramo, Italy \\ Contributions: (I) Conception and design: D Divisi, G Zaccagna; (II) Administrative support: None; (III) Provision of study materials or patients: All \\ authors; (IV) Collection and assembly of data: D Divisi, G Zaccagna; (V) Data analysis and interpretation: All authors; (VI) Manuscript writing: All \\ authors; (VII) Final approval of manuscript: All authors. \\ Correspondence to: Duilio Divisi, MD, PhD. Piazza Italia 1, 64100 Teramo, Italy. Email: duilio.divisi@aslteramo.it.
}

Background: In surgically fit non-small cell lung cancer (NSCLC) patients, pulmonary lobectomy still represents the standard of care. In recent years, the development of minimally invasive video-assisted techniques has reduced perioperative surgical stress, including patients previously thought to be unfit for surgery.

Methods: We carried out a review of literature in order to evaluate the role of the preoperative parameters in functionally compromised patients and the effectiveness of video-assisted thoracoscopic surgery (VATS) compared to the "muscle sparing" axillary mini-thoracotomy in major lung resections.

Results: Of 99 analyzed papers, we considered the 24 most significant, according to the preoperative functional status evaluation and, especially cardiac and respiratory reserve.

Conclusions: In patients with a reduced cardio-respiratory function undergoing pulmonary resection, VATS guarantees results superimposable to mini-thoracotomy and represents a valid alternative to be taken into consideration.

Keywords: Major lung resections; video-assisted thoracoscopic surgery (VATS); mini-thoracotomy; preoperative evaluation; review

Received: 23 July 2018; Accepted: 07 December 2018; Published: 24 December 2018.

doi: $10.21037 /$ shc.2018.12.04

View this article at: http://dx.doi.org/10.21037/shc.2018.12.04

\section{Introduction}

Pulmonary lobectomy represents the standard of care in early stage non-small cell lung cancer (NSCLC) patients (1-4). However, surgeons frequently have to face "high risk" patients who due to the improvement of the quality of life and the increase of the average age, constitute a pulmonary or cardiac reserve and comorbidity indexes would require major pulmonary resections (5-8). According to the 2016 Italian Association of Medical Oncology (AIOM) guidelines about the management of lung cancer (9), the most frequent complications following pulmonary resection are: cardiac arrhythmias, atelectasis, lung infections, prolonged air loss, acute respiratory distress syndrome (ARDS), respiratory insufficiency, heart failure, hemothorax, bronchial fistula, pleural empyema, pulmonary embolism and surgical wound infections. The overall postoperative mortality rate ranges from $2 \%$ to $5 \%$ in lung lobectomies and $5 \%$ to $10 \%$ in pneumonectomies $(9,10)$. For these reasons, preoperative assessment, in particular of the respiratory reserve, becomes essential to exclude predicted high-risk patients. Lee et al. (11), evaluating data on 4,315 patients aged more than 50 years old undergoing different surgical procedures (orthopedics, vascular, thoracic and abdominal surgery) and analyzing postoperative cardio-circulatory complications (56 patients, approximately $2 \%$ of 2,893 patients assigned 
Table 1 Risk class according to Brunelli et al. (12)

\begin{tabular}{lllll}
\hline Variable & Class A & Class B & Class C & Class D \\
\hline Score & 0 & $1-1.5$ & $2-2.5$ & $>2.5$ \\
Percentage of risk & $1.5 \%$ & $5.8 \%$ & $19 \%$ & $23 \%$ \\
Cardiological examination & Not necessary & Not necessary & Yes & Yes \\
Echocardiogram & Not necessary & Not necessary & Yes (in case of & Yes (in case of \\
& & & suspected pathology) & suspected pathology) \\
\hline
\end{tabular}

to derivation cohort) identified six independent predictive factors and included them in a Revised Cardiac Risk Index (RCRI): (I) high-risk type of surgery; (II) history of ischemic heart disease; (III) history of congestive heart failure; (IV) history of cerebrovascular disease; (V) preoperative treatment with insulin; (VI) preoperative serum creatinine $>2.0 \mathrm{mg} / \mathrm{dL}$. These parameters were then reviewed by Brunelli et al. (12) considering only major pulmonary resection interventions. Out of 1,696 patients undergoing surgery (1,426 lung pulmonary lobectomy and 270 pneumonectomy), four parameters were considered by assigning an item score: cerebrovascular disease (1.5 points), cardiac ischemia (1.5 points), renal disease (1 point), and pneumonectomy (1.5 points). The percentage of risk of developing complications varied according to the score, allowing the identification of different risk classes (class A, score 0, risk 1.5\%; class B, score $1-1.5$, risk $5.8 \%$; class C, score $2-2.5$, risk $19 \%$; class D, score $>2.5$, risk $23 \%$ ). In particular, in case of a score $>2$, patients should undergo a cardiological examination and, in case of suspected pathology (valvulopathy, ventricular dysfunction, pulmonary arterial hypertension), an echocardiogram with subsequent prompt treatments should be considered (Table 1). The evaluation of respiratory function must be performed through spirometry and the calculation of diffusion lung CO (DLCO) (12-14); based on results, patients could be classified into low (with values $>60-75 \%$ ), moderate (with value between $35 \%$ and $60 \%$ ) or high operative risk $(<35 \%)$. Another fundamental parameter is the forced expiratory volume in the 1st second (FEV1) $(13,15)$. Licker et al. (15), based on the results of a study conducted on 1,222 patients who underwent pulmonary resection by mini-thoracotomy and divided into three groups (728 patients with FEV1 $>70 \%$; 397 patients with FEV1 between 50\% and $70 \%$; 97 patients with FEV1 $<50 \%$ ), showed that the risk of developing postoperative respiratory complications is greater in patients with reduced FEV1 (risk equal to $10 \%$, $25 \%$ and $27 \%$ respectively in the three groups) and have calculated the reference cut-off value of FEV1 predictive of respiratory complications equal to $60 \%$, under which value, the risk increases considerably. In the assessment of the respiratory reserve, in addition to FEV1, many authors consider other parameters such as postoperative predictive (ppo) FEV1 (ppo FEV1); DLCO and postoperative predictive DLCO (ppo DLCO) $(13,16,17)$. According to the ACCP guidelines (13), if these values are $>60 \%$, patients are considered to be at low risk and, in these cases, pulmonary lobectomy or even pneumonectomy can be safely performed; in case of DLCO ranging from $30 \%$ to $60 \%$, further tests such as the "stair climb test", the "shuttle walk test" or the calculation of the maximum volume of oxygen consumed in 1 minute (VO2max) should be considered. The possibility of recruiting patients for pulmonary resection has increased in recent years thanks to the introduction of minimally invasive techniques. The advent of video-assisted thoracoscopic surgery (VATS) has made it possible to consider "functionally compromised" patients for surgery. Compared to the minithoracotomy, a minimally invasive technique, reduced the size of accesses and did not significantly compromise respiratory mechanics $(18,19)$.

\section{Methods}

A literature review through a PubMed - MEDLINE database was performed according to the following research terms: thoracotomy, video assisted thoracoscopic surgery, preoperative evaluation, lung resection. Ninety-nine papers published in the last fifteen years were found and, of them, thirty were included in our study according to our selection criteria, such as preoperative cardiologic evaluation, preoperative and predicted postoperative FEV1 and DLCO evaluation, outcomes in patients undergoing major lung resection in VATS/mini-thoracotomy (Figure 1).

\section{Results}

VATS was characterized by longer execution times but 


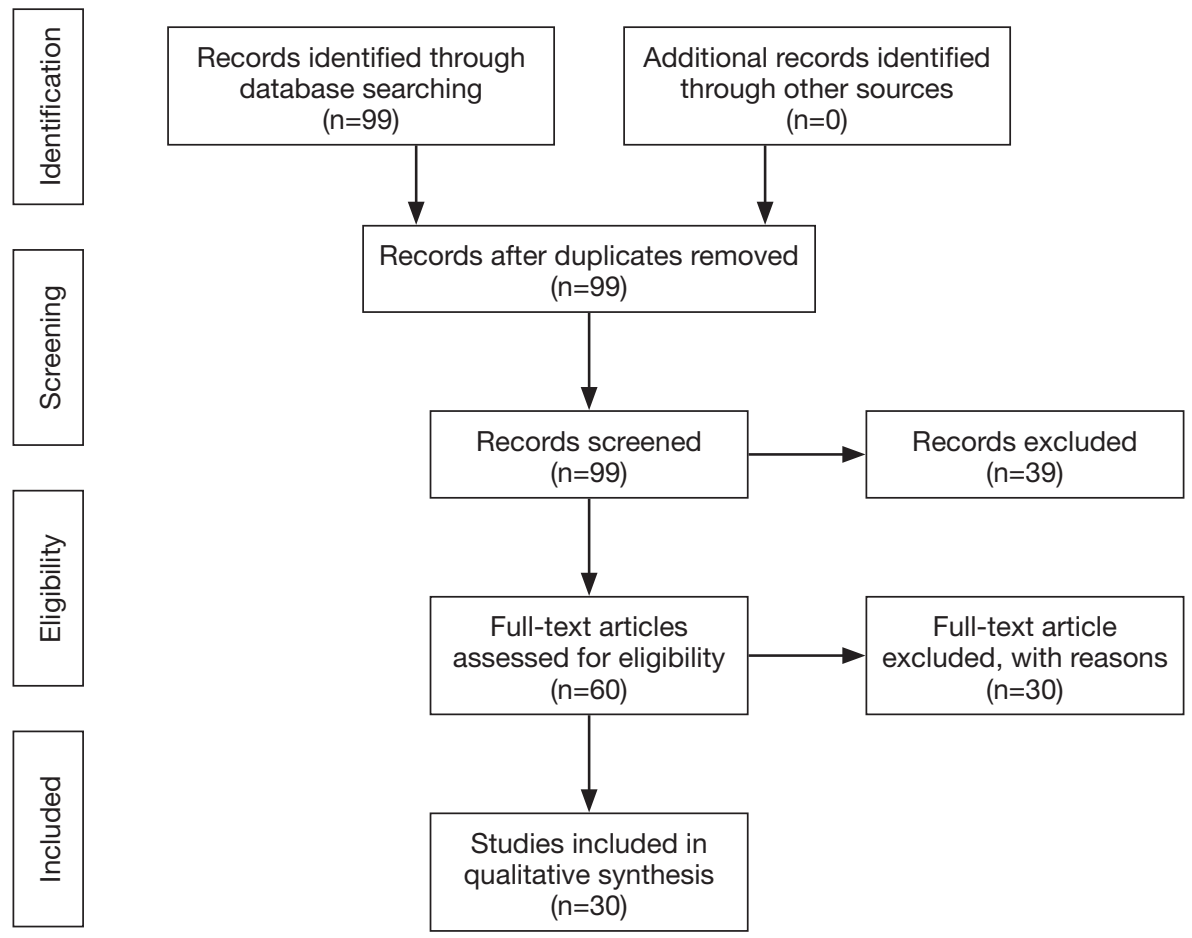

Figure 1 Explaining study design flowchart.

offers shorter hospitalization times (6.1 vs. 7.5 days) and a lower complication rate $(4.6 \%$ vs. $8.2 \%)$. From the analysis, we found that in the treatment of NSCLC, VATS is superimposable to mini-thoracotomy in terms of effectiveness and oncological radicality and offers indisputable advantages especially in functionally compromised patients. In this category VATS allowed to obtain disease free survival (DFS) and overall survival (OS) values for clinical/pathological stage I not inferior to open surgery $(88 \% / 91.5 \%$ and $94.1 \% / 94.8 \%$ vs. $77.1 \% / 93.8 \%$ and $81.8 \% / 96.2 \%$ respectively), reducing the risk of complications and the mortality rate in case of reduced cardio-pulmonary reserve $(10.4-12.8 \%$ vs. $14.9-21.9 \%$ and $0.7-2.0 \%$ vs. $4.8-5.2 \%)$. VATS allowed major pulmonary resection even in patients with FEV1 and DLCO values $<60 \%$ or affected by COPD who could not undergo the same surgery by mini-thoracotomy, achieving the same radical results of open surgery. In fact, VATS improved the outcome and decreased the surgical stress with a lower complication rate than open surgery $(17.8 \% \mathrm{vs}$. $21.7 \%$ and $22 \%$ vs. $32.9 \%$ respectively).

\section{Discussion}

Since its introduction, VATS has undergone a continuous evolution and is now considered equivalent to open surgery for the treatment of early-stage lung cancer in terms of safety, efficacy and radical excision. A considerable boost to the development of this technique comes from the possibility that it offers major pulmonary resection even in patients with reduced cardio-pulmonary reserve due to less invasiveness and surgical stress; moreover, in patients with NSCLC it proved to be a feasible and effective technique not only in lobectomies but also in segmentectomies (20). Over the last few years, many studies have been conducted that attest to the superiority of VATS compared to thoracotomy. Zhao et al. (21) compared the results of the two methods on a sample of 1,083 patients who underwent pulmonary lobectomy and lymphadenectomy for early stage pulmonary neoplasia (cT1M0N0). In 560 patients a "muscle sparing" open access was used while 523 patients underwent VATS lobectomy. The analysis of the data showed that the video-assisted technique is characterized by longer times (98.8 vs. $77.8 \mathrm{~min}$ ) and a smaller number of resected lymph nodes (12.6 vs. 18.2); however, the period of hospitalization was shorter (6.1 vs. 7.5 days) thanks also to the shorter drainage time and above all the index of postoperative complications was lower $(4.6 \%$ vs. $8.2 \%$ ) while maintaining the same long-term survival 
outcomes. The effectiveness of VATS in terms of longterm survival has also been demonstrated by Higuchi et al. (22). One-hundred and sixty patients with stage I NSCLC underwent pulmonary lobectomy (114 in VATS and 46 in thoracotomy). Patients were divided into two groups according to the staging criteria (clinical stage and pathological stage) and were checked every 2-3 months for the first 12 months after surgery and thereafter every 6 months up to 5 years. In patients undergoing VATS, the DFS was equal to $88 \%$ and $91.5 \%$ for the clinical stage and pathological stage respectively; while the 5 -year OS was $94.1 \%$ and $94.8 \%$. In patients undergoing thoracotomy the values were equal to $77.1 \%$ and $93.8 \%$ for DFS, $81.8 \%$ and $96.2 \%$ for OS respectively in the two groups. This study demonstrates that in terms of survival, VATS is not inferior to thoracotomy. According to Salati et al. (23) VATS does not offer real advantages in terms of functional recovery compared to open. Evaluating 195 patients who underwent lobectomy in VATS (83 patients) or in open (112 patients) 3 months after surgery, noted that the reduction in respiratory function was not significantly different between the two approaches. Preoperative FEV1 mean in VATS patients and "open" patients was $93.2 \%$ and $84.8 \%$, respectively, whereas DLCO was $77 \%$ and $82.8 \%$. At 3 months from the intervention the reductions calculated in the two parameters were respectively $7.2 \%$ and $10.6 \%$ in VATS patients and $10 \%$ and $11.9 \%$ in "open" patients. On the other hand, the effectiveness of the minimally invasive technique in patients with reduced functional reserve is widely reported in literature. Burt et al. (24) conducted a study on 13,376 patients who underwent pulmonary lobectomy, $49.1 \%$ in VATS and $50.9 \%$ in open; all patients showed ppo FEV1 and ppo DLCO $<40 \%$. Results revealed that the mortality rate is lower in the VATS group (0.7-2.0\%) compared to the "open" group (4.8-5.2\%) as well as the complication rate, equal to $10.4-12.8 \%$ in the VATS group and $14.9-21.9 \%$ in the "open" group. Several authors encourage the use of VATS also in patients with COPD. Jeon et al. (25) report the results of 1,502 patients with NSCLC; $446(29.7 \%)$ were diagnosed COPD and 283 were selected among them as having stage I NSCLC. One-hundred and sixty patients underwent VATS lobectomy and 123 patients thoracotomy. The overall incidence of complications was $32.9 \%$ in patients undergoing thoracotomy and $22.0 \%$ in the VATS group, while pulmonary complications occurred in $12.1 \%$ of open patients and only $1.1 \%$ in VATS patients. In addition, the period of hospitalization was significantly shorter in patients who underwent VATS lobectomy (6 vs.
9 days). The advantages of VATS in patients with limited pulmonary function are also confirmed in a review by Oparka et al. (26) who analyzed 280 papers. Data show that VATS is preferable not only in patients with ppo FEV $1<60 \%$ because it allows a reduction in the complication rate compared to thoracotomy (17.8\% vs. $21.7 \%$ ) (27) but also in patients with FEV1 ppo $<40 \%$ in which the incidence of pneumonia falls from $21.7 \%$ to $4.3 \%$ in patients subjected to VATS (28) and the 5 -year survival ranges from $18 \%$ to $42 \%$ (29). Significant data are analyzed in the work of Begum et al. (30) about the role of VATS in patients with reduced VO2max. The data come from the ESTS database and concern 1,684 patients undergoing lobectomy (281 in VATS and 1403 in thoracotomy); of these, 471 (28\%) had a low VO2max $(<15 \mathrm{~mL} / \mathrm{kg} / \mathrm{min})$ and were subjected to VATS (72 patients) or thoracotomy (399 patients). The overall complication rate was similar in the two groups (with regard to cardiopulmonary complications in the two groups, they occurred in $18 \%$ and $36 \%$, respectively, the mortality rate was five times higher in patients undergoing thoracotomy (1.4\% vs. 6.7\%).

\section{Conclusions}

Based on the data collected, VATS is a safe and effective technique and must always be considered in the treatment of surgically treatable pulmonary pathologies or early-stage pulmonary neoplasms even in functionally compromised or COPD-diagnosed patients.

\section{Acknowledgments}

The Authors thank Anne Prudence Collins for editing the English text.

Funding: None.

\section{Footnote}

Provenance and Peer Review: This article was commissioned by the editorial office, Shanghai Chest for the series "Surgical Approaches to VATS Lobectomy: Meet the Experts". The article has undergone external peer review.

Conflicts of Interest: All authors have completed the ICMJE uniform disclosure form (available at http://dx.doi. org/10.21037/shc.2018.12.04). The series "Surgical Approaches to VATS Lobectomy: Meet the Experts" was commissioned by the editorial office without any funding or sponsorship. RC served as the unpaid Guest Editor of 
the series. The authors have no other conflicts of interest to declare.

Ethical Statement: The authors are accountable for all aspects of the work in ensuring that questions related to the accuracy or integrity of any part of the work are appropriately investigated and resolved.

Open Access Statement: This is an Open Access article distributed in accordance with the Creative Commons Attribution-NonCommercial-NoDerivs 4.0 International License (CC BY-NC-ND 4.0), which permits the noncommercial replication and distribution of the article with the strict proviso that no changes or edits are made and the original work is properly cited (including links to both the formal publication through the relevant DOI and the license). See: https://creativecommons.org/licenses/by-nc-nd/4.0/.

\section{References}

1. Donahoe LL, de Valence M, Atenafu EG, et al. High Risk for Thoracotomy but not Thoracoscopic Lobectomy. Ann Thorac Surg 2017;103:1730-5.

2. Salati M, Brunelli A. Risk Stratification in Lung Resection. Curr Surg Rep 2016;4:37.

3. Ezer N, Kale M, Sigel K, et al. Outcomes after Videoassisted Thoracoscopic Lobectomy versus Open Lobectomy for Early-Stage Lung Cancer in Older Adults. Ann Am Thorac Soc 2018;15:76-82.

4. Ghanem S, El Bitar S, Hossri S, et al. What we know about surgical therapy in early-stage non-small-cell lung cancer: a guide for the medical oncologist. Cancer Manag Res 2017;9:267-78.

5. Mery CM, Pappas AN, Bueno R, et al. Similar long-term survival of elderly patients with non-small cell lung cancer treated with lobectomy or wedge resection within the surveillance, epidemiology, and end results database. Chest 2005;128:237-45.

6. Burfeind WR Jr, Tong BC, O'Branski E, et al. Quality of life outcomes are equivalent after lobectomy in the elderly. J Thorac Cardiovasc Surg 2008;136:597-604.

7. Bernard A, Ferrand L, Hagry O, et al. Identification of prognostic factors determining risk groups for lung resection. Ann Thorac Surg 2000;70:1161-7.

8. Berry MF, Hanna J, Tong BC, et al. Risk factors for morbidity after lobectomy for lung cancer in elderly patients. Ann Thorac Surg 2009;88:1093-9.

9. Available online: http://media.aiom.it/userfiles/files/doc/
LG/2016_LG_AIOM_Polmone.pdf

10. Shah SH, Goel A, Selvakumar V, et al. Role of pneumonectomy for lung cancer in current scenario: An Indian perspective. Indian J Cancer 2017;54:236-40.

11. Lee TH, Marcantonio ER, Mangione CM, et al. Derivation and prospective validation of a simple index for prediction of cardiac risk of major non cardiac surgery. Circulation 1999;100:1043-9.

12. Brunelli A, Varela G, Salati M, et al. Recalibration of the revised cardiac risk index in lung resection candidates. Ann Thorac Surg 2010;90:199-203.

13. Brunelli A, Kim AW, Berger KI, et al. Physiologic evaluation of the patient with lung cancer being considered for resectional surgery: Diagnosis and management of lung cancer, 3rd ed: American College of Chest Physicians evidence-based clinical practice guidelines. Chest 2013;143:e166S-90S.

14. Sandri A, Papagiannopoulos K, Milton R, et al. Highrisk patients and postoperative complications following video-assisted thoracic surgery lobectomy: a case-matched comparison with lower-risk counterparts. Interact Cardiovasc Thorac Surg 2015;21:761-5.

15. Licker MJ, Widikker I, Robert J, et al. Operative mortality and respiratory complications after lung resection for cancer: impact of chronic obstructive pulmonary disease and time trends. Ann Thorac Surg 2006;81:1830-7.

16. Novoa NM, Esteban P, Rodriguez M, et al. Functional evaluation before lung resection: searching for a low technology test in a safer environment for the patient: a pilot study. Eur J Cardiothorac Surg 2017;51:856-60.

17. Zhang R, Lee SM, Wigfield C, et al. Lung function predicts pulmonary complications regardless of the surgical approach. Ann Thorac Surg 2015;99:1761-7.

18. Cui F, Liu J, Shao W, et al. Thoracoscopic minimally invasive surgery for non-small cell lung cancer in patients with chronic obstructive pulmonary disease. J Thorac Dis 2013;5 Suppl 3:S260-6.

19. Wang W, Xu Z, Xiong X, et al. Video-assisted thoracoscopic lobectomy for non-small cell lung cancer in patients with severe chronic obstructive pulmonary disease. J Thorac Dis 2013;5 Suppl 3:S253-9.

20. Linden $D$, Linden $K$, Oparka J. In patients with resectable non-small-cell lung cancer, is video-assisted thoracoscopic segmentectomy a suitable alternative to thoracotomy and segmentectomy in terms of morbidity and equivalence of resection? Interact Cardiovasc Thorac Surg 2014;19:107-10.

21. Zhao Y, Li G, Zhang Y, et al. Comparison of outcomes between muscle-sparing thoracotomy and video-assisted 
thoracic surgery in patients with cT1 N0 M0 lung cancer. J Thorac Cardiovasc Surg 2017;154:1420-9.e1.

22. Higuchi M, Yaginuma H, Yonechi A, et al. Long-term outcomes after video-assisted thoracic surgery (VATS) lobectomy versus lobectomy via open thoracotomy for clinical stage IA non-small cell lung cancer. J Cardiothorac Surg 2014;9:88.

23. Salati M, Brunelli A, Xiumè F, et al. Video-assisted thoracic surgery lobectomy does not offer any functional recovery advantage in comparison to the open approach 3 months after the operation: a case matched analysis. Eur J Cardiothorac Surg 2017;51:1177-82.

24. Burt BM, Kosinski AS, Shrager JB, et al. Thoracoscopic lobectomy is associated with acceptable morbidity and mortality in patients with predicted postoperative forced expiratory volume in 1 second or diffusing capacity for carbon monoxide less than $40 \%$ of normal. J Thorac Cardiovasc Surg 2014;148:19-28.

25. Jeon JH, Kang CH, Kim HS, et al. Video-assisted thoracoscopic lobectomy in non-small-cell lung cancer patients with chronic obstructive pulmonary disease is associated with lower pulmonary complications than open lobectomy: a propensity score-matched analysis. Eur J

doi: 10.21037/shc.2018.12.04

Cite this article as: Divisi D, Zaccagna G, Barone M, Crisci R. Preoperative function evaluation of the major lung resection: muscle-sparing axillary mini-thoracotomy versus video-assisted thoracoscopic surgery. Shanghai Chest 2018;2:98.
Cardiothorac Surg 2014;45:640-5.

26. Oparka J, Yan TD, Ryan E, et al. Does video-assisted thoracic surgery provide a safe alternative to conventional techniques in patients with limited pulmonary function who are otherwise suitable for lung resection? Interact Cardiovasc Thorac Surg 2013;17:159-62.

27. Ceppa DP, Kosinski AS, Berry MF, et al. Thoracoscopic lobectomy has increasing benefit in patients with poor pulmonary function: a society of thoracic surgeons database analysis. Ann Surg 2012;256:487-93.

28. Kachare S, Dexter EU, Nwogu C, et al. Perioperative outcomes of thoracoscopic anatomical resections in patients with limited pulmonary reserve. J Thorac Cardiovasc Surg 2011;141:459-62.

29. Lau KK, Martin-Ucar AE, Nakas A, et al. Lung cancer surgery in the breathless patient-the benefits of avoiding the gold standard. Eur J Cardiothorac Surg 2010;38:6-13.

30. Begum SS, Papagiannopoulos K, Falcoz PE, et al. Outcome after video-assisted thoracoscopic surgery and open pulmonary lobectomy in patients with low VO2 max: a case-matched analysis from the ESTS database. Eur J Cardiothorac Surg 2016;49:1054-8. 